\title{
Pre-Post Washing Comparison for Horizontal Wicking Behavior of Three Types of Knits in Different Fiber- Contents
}

\author{
Usha Chowdhary ${ }^{1 *}$, Mohammed Maruf Adnan ${ }^{1}$ and Ching I Cheng ${ }^{2}$ \\ ${ }^{1}$ Fashion Merchandising and Design, Central Michigan University, USA \\ ${ }^{2}$ Department of Mathematics, Central Michigan University, USA
}

*Corresponding author: Usha Chowdhary, Professor, Department of Human Environmental Studies, Fashion Merchandising and Design, Central Michigan University, USA.

Received Date: May 17, 2019

Published Date: May 24, 2019

\begin{abstract}
The study examined pre and post wash horizontal wicking of interlock, jersey and pique knits in various fiber-contents using AATCC 198-2013. Impact of weight, thickness and count was also examined. Multiple regression, paired t-test and repeated measure one factor test were used to test the hypotheses. Findings revealed that collectively all types of knits had higher wicking in post than pre-wash state. Differences were significant for different knit structures for different fiber contents. Effect of wash as well as type of knit was found to be significant. Weight, thickness and count contributed differentially to the wicking ability of knits in pre and post wash settings. Results have implications for future research and use where comfort and moisture management are important considerations.
\end{abstract}

Keywords: Horizontal wicking; Pre-post washing/laundering; Moisture management; Knit fabrics; Fiber content

\section{Introduction}

The concept of wicking and moisture management gained popularity at the beginning of the new century. With an increased interest in healthy living and exercising, consumer has begun to value moisture management more than ever before. Wicking behavior of textiles is related to comfort and has gained popularity in active, casual and sportswear. Loosely knitted fabrics exhibited high air permeability, but low moisture management ability [1]. The authors also asserted that an increase in fabric count decreased air permeability, but improved moisture management [2]. However, they did not address so for different types of weft knits.

Another researcher reported that fabric thickness slowed the vertical wicking process. However, an increase in elastane increased the wicking height [3]. The impact of washing on several structural attributes and dimensional stability was examined in another study [4]. The findings revealed that repeated laundering resulted in increased weight, thickness, shrinkage, dimensional stability and cover factor of the woven fabric. Similar findings were reported in another study for jersey knit except the cover factor that was not examined [4]. Prior research did not consider different types of knits and fiber contents in one study collectively for understanding wicking behavior of knitted fabrics comprehensively.
Tortora and Merkel (629-630) defined wicking as the "passage of liquid through or along the interstices in a permeable material" [5]. AATCC unofficially published some of the techniques to measure absorbency and moisture management in 2004. Even though the concept of understanding the importance of wicking behavior has been of utmost importance to textile manufacturers, retailers and chemical suppliers, the first two standards for vertical and horizontal wicking were not developed until 2013 [6]. These tests use time and spread to calculate the wicking rate. The manual defines wicking as the movement of the liquid through capillary action across the material.

Wicking helps with moisture management that results in comfort for the heating body in the hot weathers and transitioning body in the changing weathers. Despite the movement of moving toward understanding wicking behavior literature had limited information on variety of knits that are available in the market. Some researchers reported that wicking gets better after laundering [47]. Another study found that it reduced after washing the garment due to tightness resulting from shrinkage and left-over residue of detergent [4]. Additionally, impact of structural attributes such as fiber content, count, thickness, and weight are generally reported 
in several studies for selected fabric constructions in a limited manner. The tightness and increased thickness could impact horizontal wicking adversely and needs to be examined further. One study (Telli \& Ozdil, 2015) examined the impact of recycled PET on several performance attributes including dimensional stability [8]. Another study reported on impact of different knit structures and fiber contents on bursting strength and extension [9]. However, none of the previous studies examined three types of knits for different fiber contents collectively to demonstrate the differing behavior for horizontal wicking. Therefore, the reported study was undertaken to examine horizontal wicking for three types of knits. The purpose of the study was twofold. First, to demonstrate that fabrics with different fiber contents could differ for their wicking ability. Second, same fiber content could differ in washed and unwashed forms.

\section{Literature Review}

Literature review provides some studies that examined relationship between body comfort and wicking behavior. Three brands of $100 \%$ cotton t-shirts were examined for horizontal wicking within the context of frequency of washing with commercial detergent [4]. Findings revealed that wicking increased significantly for all three brands of $t$ shirts between $5^{\text {th }}$ and $25^{\text {th }}$ wash. Polyester with core of cotton had better wicking ability than regular polyester/cotton blend [10]. Double faced knitted fabrics (cotton to cotton, poly propylene to polypropylene or combinations thereof) had better moisture management [11]. Modified polyester has better moisture management than cotton alone. They also noted that warp knits have better wicking ability than the tubular knits [12]. Polyester was recommended as next to skin layer and cotton as outer layer for effective moisture management. Authors also stressed the need to consider linear density for plated fabrics made from polyester and cotton. polyester for its moisture management for next to skin apparel in another study [13]. They recommended finer yarns for inner layer (11-26 Tex) and coarser yarns for the outer layer (29-33 Tex). Hussain, Nazir and Masood reported that double knit jersey structure (Outer and inner surfaces are made from different fibers) has better water transporting ability than rib knit fabrics that also have double structure [14].

The scholars also reported that reduction in stitch length improved moisture management. Another publication reported that interlock structures have poor wicking ability because of the air trapped in the loose structures. It enhances insulation but decreases moisture management [15]. Oner and Okur examined several knit types and structures [16]. Their findings revealed that structures with floats had higher moisture management and wicking than the fabrics without floats. They also reported that tight structures have higher moisture management than loose structures. Researchers also asserted that stretched loops of longer stitches improve air permeability by increased porosity and reduce the wicking ability. Their study focused on interlock knits.

Wardingsih and Troynikov (2012) reported that increase in cover factor increased the Wetting time for bamboo fabrics [17].
Senthikumar, Sampath and Ramakrishnan emphasized the need to examine moisture management for active sportswear [18]. Cimilli, Nergis, and Ozdemir found that in their study wicking was highest for chitosan and cotton and lowest for bamboo fabrics [19]. Another research study reported that wicking area and time explain $99.87 \%$ of the variance [20]. They emphasized the need to measure wicking rate of both woven and nonwoven materials. Another study reported that cotton/spandex blend in jersey had significantly higher horizontal wicking than rayon/spandex and polyester/spandex blends [21].

To summarize the literature review, it is fair to state that none of the previous literature examined several fiber contents and different knit constructions and fiber contents simultaneously. Therefore, it was deemed meritorious to compare different types of knits and fiber contents simultaneously with same procedure for the reported study. Based on the literature reviewed, following six hypotheses were developed.

\section{Hypotheses}

Hypothesis 1: Horizontal wicking will be higher for post-wash than pre-wash for jersey, interlock and pique knits.

Hypothesis 2: No difference will exist for horizontal wicking of $100 \%$ cotton, cotton/polyester 85/15 and 50/50, rayon/polyester, rayon spandex, polyester spandex, and wool/acrylic in pre-wash and post-wash forms for jersey knit construction.

Hypothesis 3: No difference will exist for horizontal wicking of Bamboo/Spandex (95/5\%), 100\% cotton, 100\% polyester,50/50 polyester/acrylic, 95/5 and 96/4\% polyester/ spandex, and $76 / 20 / 4 \%$ rayon/wool/linen blend in pre-wash and post-wash forms. For interlock knit construction.

Hypothesis 4: Cotton and polyester will differ for horizontal wicking of 100\% cotton (light), 100\% cotton (heavy) and,100\% polyester in pre-wash and post-wash forms. For pique knit construction.

Hypothesis 5: No difference will exist between 100\% cotton in jersey, interlock, and pique knit in pre and post wash for horizontal wicking.

Hypothesis 6: Horizontal wicking is function of fabric thickness, weight and count.

\section{Experimental}

Seventeen fabrics were examined for horizontal wicking in the pre and post wash settings for interlock, jersey and pique knits. All fabrics were purchased from an internet and local retailer. Seven fabrics represented jersey knits and interlock knits each and three fabrics represented pique knits. Fabric Count, fabric thickness and weight are provided in table 1 to represent variety of fiber content and selected structural attributes. Number of observations for calculating the means presented in Table 1 was 5 for each of the selected structural attribute. 
Table 1: Means of seventeen fabrics for fabric count, thickness and weight for jersey, interlock and pique knits.

\begin{tabular}{|c|c|c|c|c|c|}
\hline S. No & Knit Type & Fibre Content & $\begin{array}{c}\text { Fabric Count } \\
\text { Wales x Courses }\end{array}$ & $\begin{array}{l}\text { Fabric Thickness } \\
\text { millimeters }\end{array}$ & $\begin{array}{c}\text { Fabric weight } \\
\text { ozs } / y^{2} d^{2}\end{array}$ \\
\hline \multicolumn{6}{|c|}{ Interlock } \\
\hline 1 & Interlock & Bamboo/Cotton 70/30 & $38 \times 38=76$ & 0.848 & 7.938 \\
\hline 2 & Interlock & $100 \%$ Cotton & $40 \times 39=79$ & 0.038 & 5.865 \\
\hline 3 & Interlock & $100 \%$ Polyester & $42 \times 54=96$ & 0.924 & 6.875 \\
\hline 4 & Interlock & Polyester/Acrylic 50/50 & $23 \times 21=44$ & 1.324 & 7.187 \\
\hline 5 & Interlock & Poly/Spandex 95/5 & $37 \times 54=91$ & 0.852 & 6.695 \\
\hline 6 & Interlock & Polyester/Spandex 96/4 & 94 & 1.456 & 7.907 \\
\hline 7 & Interlock & Rayon/Wool/Lycra 76/20/4 & $30 \times 46=76$ & 0.836 & 9.777 \\
\hline \multicolumn{6}{|c|}{ Jersey } \\
\hline 1 & Jersey & $100 \%$ cotton & 84 & 0.488 & 3.215 \\
\hline 2 & Jersey & Cotton/Polyester 85/15 & $34 \times 53=87$ & 0.74 & 4.455 \\
\hline 3 & Jersey & Cotton/Polyester 50/50 & $39 \times 53=92$ & 0.62 & 4.403 \\
\hline 4 & Jersey & Cotton/Polyester $60 / 40$ & $37 \times 51=88$ & 0.592 & 4.584 \\
\hline 5 & Jersey & Rayon/Spandex 95/5 & $42+51=93$ & 0.568 & 6.339 \\
\hline 6 & Jersey & Poly/Spandex 95/5 & $52 \times 55=107$ & 0.56 & 5.749 \\
\hline 7 & Jersey & Wool/Acrylic 45/55 & $28 \times 37=65$ & 0.748 & 4.933 \\
\hline \multicolumn{6}{|c|}{ Pique } \\
\hline 1 & Pique & $100 \%$ Cotton & $30 \times 35=65$ & 0.76 & 4.515 \\
\hline 2 & Pique & $100 \%$ Cotton & $30 \times 48=78$ & 0.872 & 6.449 \\
\hline 3 & Pique & $100 \%$ Polyester & $44 \times 54=102$ & 0.504 & 4.045 \\
\hline
\end{tabular}

ASTM D 1777 - 96 (Reapproved 2015) was used for fabric thickness [22]. Fabric weight was calculated based on ASTM D3776/3776M - 09a (Reapproved 2017) [23]. Fabric weight was represented in ounces per square yard. ASTM D 3887 - 96 (Reapproved 2008) was used for fabric count [24]. Fabric count was measured in number of wales and courses per inch. Fabric thickness was measured in millimeters. Several research studies have suggested that structural attributes impact performance attributes. Therefore, a variety of blends as well as pure fabrics were selected. Information in Table 1 should allow reader to put findings in perspective.

Horizontal wicking was examined for three different constructions inclusively and exclusively and several different fiber contents. AATCC 96-2012 was modified to for laundering the specimens to determine the impact of washing on horizontal wicking. Modification represented change in sample size from 16" x 16 " for knitted fabrics to 8" x 8" that is required for horizontal wicking. AATCC 198 -2013 method was used for testing6. Five specimens of 8" x 8" dimensions were used for seven fiber contents each in jersey and interlock and three for pique knits. The formula below was used to calculate horizontal wicking in $\mathrm{mm}^{2} / \mathrm{sec}$. Time used for test was 300 seconds.

$$
W=p(1 / 4)\left(d_{1}\right)\left(d_{2}\right) / t
$$

Wicking rate $=\mathrm{W}$

$\mathrm{d}_{1}=$ Wicking distance in width

$\mathrm{d}_{2}=$ Wicking distance in length

$\mathrm{t}=$ Wicking time in seconds
All fabrics were conditioned using ASTM -D1776 procedure [25]. Ten milliliter (1cc) water was dispensed from burette on a specimen on the embroidery hoop from 1" distance at the center of the hoop. Distance covered was measured in both directions. The process was repeated 5 times and means and standard deviation were calculated for each fabric construction and fiber content [26]. The means and standard deviations were then used for comparing each fabric in pre and post wash forms for testing the hypothesis. A paired t-test was used for hypothesis 1-4. The confidence level for accepting or rejecting the hypothesis was set at 95\%. For hypothesis 5 , repeated measure with one factor was used to examine main effect of wash (pre and post), the main effect of structure (jersey, interlock, pique), and interaction between wash and structure. A multiple regression model was used for hypothesis 6 .

Hypothesis 1: Horizontal wicking will be higher for post-wash than pre-wash for jersey, interlock and pique knits.

Results from a paired t-test analysis revealed that post washed fabrics in all three knits had significantly higher wicking than the pre-wash conditions (Table 2). Figure 1 visually reflects this phenomenon. Hypothesis I was accepted. Green color represents results of pre-wash and yellow of the post-wash. Maximum change was observed for pique knit followed the interlock and jersey knit. This finding is consistent with a patent which claimed that pique knit has higher ability to wick and manage moisture due to irregular surface than interlock and jersey knits. Wicking was also noted to be better for a double face knit that had smoother outer layer and irregular inner layer [27]. In literature, mixed results are found between laundering and wicking. 


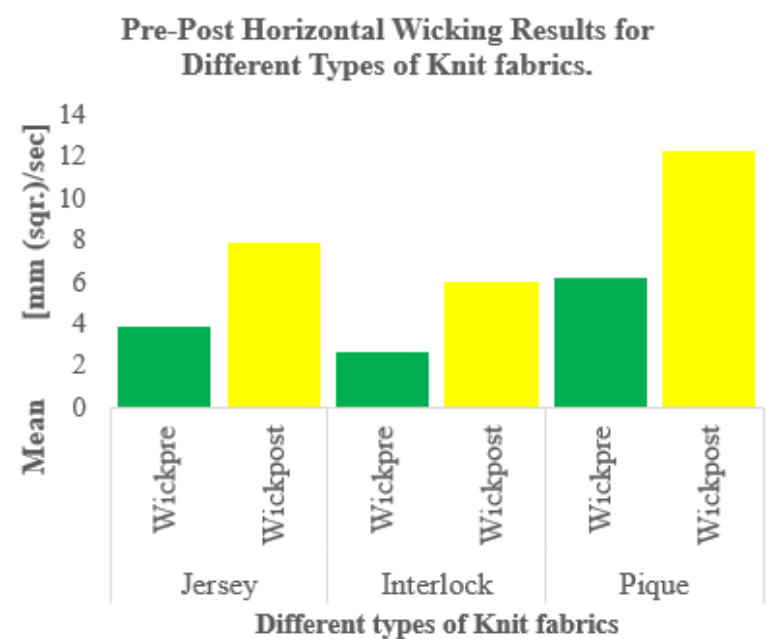

Figure 1: Pre- post horizontal wicking results for different types of knit fabrics.

Table 2: T-tests for pre-post horizontal wicking for jersey, interlock and pique knits.

\begin{tabular}{|c|c|c|c|c|}
\hline $\begin{array}{c}\text { Construction/ } \\
\text { Post/Pre }\end{array}$ & $\begin{array}{c}\text { Mean } \mathbf{m m}^{2} / \\
\text { sec }\end{array}$ & $\begin{array}{l}\text { Standard } \\
\text { Deviation }\end{array}$ & t-Value & p Value \\
\hline \multicolumn{5}{|l|}{ Jersey $(n=35)$} \\
\hline Post-Wash & 7.883 & 7.858 & 6.337 & 0.001 \\
\hline Pre-Wash & 3.886 & 5.766 & & \\
\hline \multicolumn{5}{|c|}{ Interlock $(n=35)$} \\
\hline \multicolumn{5}{|l|}{ Post-Wash } \\
\hline \multirow[t]{2}{*}{ Pre-Wash } & 6.006 & 7.224 & 3.307 & 0.002 \\
\hline & 2.635 & 3.905 & & \\
\hline \multicolumn{5}{|l|}{ Pique $(n=15)$} \\
\hline Post-Wash & 12.234 & 3.143 & 3.408 & 0.004 \\
\hline Pre-Wash & 1.381 & 0.11 & & \\
\hline
\end{tabular}

General thinking is that washing textiles enhances its wicking ability of towels because temporary finish applied to the product is removed. However, others believe that dimensional change (shrinkage) and retention of cleaning supplies can increase thickness and weight and that could impact wicking adversely [3]. Repeating this work by controlling the structural attributes like yarn size, yarn twist, fabric weight and/or cotton can help understanding the conflicting results better.

Hypothesis 2: No difference will exist for horizontal wicking of $100 \%$ cotton, cotton/polyester, rayon/polyester, rayon spandex, polyester spandex, and wool/acrylic in pre-wash and post-wash forms for jersey knit construction.

A paired t-test analysis revealed that differences between pre and post laundering were significant for all fiber contents except $100 \%$ cotton (Table 3). Figure 2 demonstrates this phenomenon visually. Hypothesis 2 was rejected. It is worth noting that wicking rate was the highest for the cotton/polyester (50/50 blend). It may be due to changed absorption power of cotton after adding polyester in different proportions. Even though previous research did not test horizontal wicking, Merkel noted that poly cotton blend burns faster than $100 \%$ cotton alone [16]. However, it is inconsistent with the assertion of Cohen and Johnson who reported that a 50/50\% polyester/cotton blend is less comfortable than $100 \%$ cotton for hot and humid weather because polyester absorbs less water [1]. The reported study indicates that poly/cotton blend has better wicking despite the hydrophobic nature of $100 \%$ polyester. Hussain et al. reported that moisture management of jersey knit fabric made from bamboo was impacted by its cover factor [14]. They noted that increase in the cover factor decreased the ability of transporting liquid. Another research study by Chatterjee and Singh examined polyester under three different tensions using vertical wicking method [28]. They noted that wicking is function of micro (between fibers) and macro (between yarns) capillary action. They used different tensions by changing weights from 3 grams to 12,20 and 34 grams.

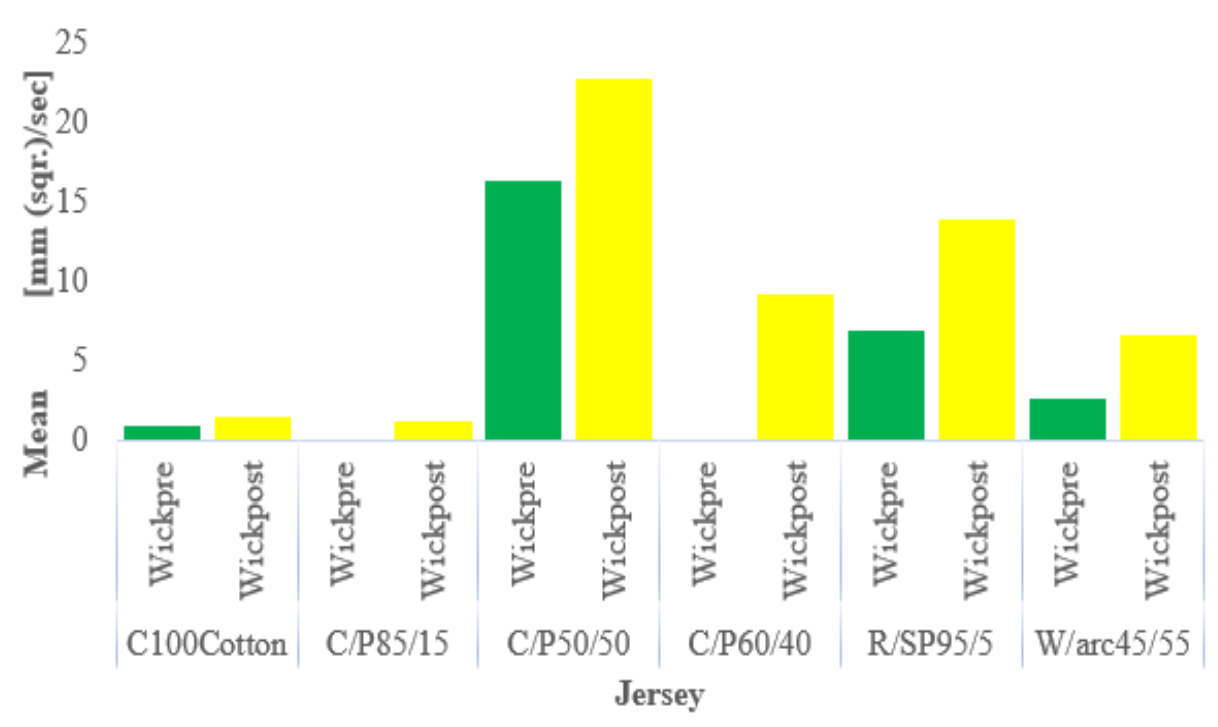

Figure 2: Pre- post horizontal wicking results for jersey knits. 
Table 3: T-tests for pre-post horizontal wicking for jersey knits in different fiber content.

\begin{tabular}{|c|c|c|c|c|}
\hline Jersey/ Post/Pre-Fiber Content & Mean mm2/sec & Standard Deviation & t-Value & p Value \\
\hline \multicolumn{5}{|l|}{$100 \%$ Cotton Light Weight $(n=5)$} \\
\hline Post-Wash & 1.488 & 0.667 & 1.582 & 0.189 \\
\hline Pre-Wash & 0.947 & 0.106 & & \\
\hline \multicolumn{5}{|l|}{ Cotton/Polyester $(85 / 15)(n=5)$} \\
\hline Post-Wash & 1.166 & 0.529 & 4.931 & 0.008 \\
\hline Pre-Wash & 0.000 & 0.000 & & \\
\hline \multicolumn{5}{|l|}{ Cotton/Polyester $(50 / 50)(n=5)$} \\
\hline Post-Wash & 22.827 & 1.562 & 5.335 & 0.006 \\
\hline Pre-Wash & 16.352 & 1.57 & & \\
\hline \multicolumn{5}{|l|}{ Cotton/Polyester $(60 / 40)(n=5)$} \\
\hline Post-Wash & 9.193 & 2.563 & 8.02 & 0.001 \\
\hline Pre-Wash & 0.000 & 0.000 & & \\
\hline \multicolumn{5}{|l|}{ Rayon/Spandex (95/05) $(n=5)$} \\
\hline Post-Wash & 13.878 & 1.265 & 5.445 & 0.006 \\
\hline Pre-Wash & 6.91 & 2.056 & & \\
\hline \multicolumn{5}{|l|}{ Polyester/Spandex $(95 / 05)(n=5)$} \\
\hline Post-Wash & 0 & 0 & No Test Performed & \\
\hline Pre-Wash & 0 & 0 & & \\
\hline \multicolumn{5}{|l|}{ Wool/Acrylic (45/55) $(n=5)$} \\
\hline Post-Wash & 6.626 & 0.322 & 9.236 & 0.001 \\
\hline Pre-Wash & 2.616 & 0.929 & & \\
\hline
\end{tabular}

Hypothesis 3: No difference will exist for horizontal wicking of Bamboo/Spandex (95/5\%), 100\% cotton, 100\% polyester,50/50 polyester/acrylic, $95 / 5$ and $96 / 4 \%$ polyester/ spandex, and 76/20/4\% rayon/wool/linen blend in pre-wash and post-wash forms for interlock knit construction.

Findings revealed that except for bamboo/spandex blend and rayon/wool linen blend wicking improved for all other fabrics significantly (Table 4). Hypothesis 3 was rejected. It was highest for the $50 / 50$ poly acrylic blend and lowest for the poly spandex blends. It appears that combining hydrophobic fabric with hydrophilic fabric improves wicking more than combining two hydrophobic fibers. Further testing is needed to confirm this assertion. A significant increase in the wicking ability of all fiber contents except bamboo/spandex is inconsistent with the assertion of Hussain et al. who reported that increased loop length in interlock knits results in poor moisture management properties [14]. For the reported study wicking ability increased after washing that can cause some shrinkage and reduce stitch length rather than increasing it. Bamboo is generally added for its moisture management superiority. In the reported study, means were very high for bamboo/Spandex as opposed to other blends for prewash setting. However, differences were not significant for this blend between pre and post wash setting. In fact, they dropped slightly after washing. Study needs to be repeated for better understanding of this relationship. Low and nonsignificant ability of rayon/wool/Lycra could not be explained. Only Lycra has $1 \%$ moisture regain bur wool and rayon have higher ability to hold moisture. Furthermore, acrylic does have slightly higher ability than spandex to hold moisture [1]. This may have contributed toward higher wicking of poly/acrylic over poly/ spandex blends. Additional research is needed to rationalize this finding (Figure 3).

Table 4: T-tests for pre-post horizontal wicking for interlock knits in different fiber contents.

\begin{tabular}{|c|c|c|c|c|}
\hline Interlock /Post/Pre/Fiber Content & Mean mm2/sec & Standard Deviation & t-Value & p Value \\
\hline \multicolumn{5}{|l|}{ Bamboo/Spandex $(95 / 5,=5)$} \\
\hline Post-Wash & 12.454 & 0.713 & 0.912 & 0.413 \\
\hline Pre-Wash & 11.666 & 1.578 & & \\
\hline \multicolumn{5}{|l|}{$100 \%$ Cotton $(\mathrm{n}=5)$} \\
\hline Post-Wash & 5.11 & 0.52 & 15.694 & 0.001 \\
\hline Pre-Wash & 1.179 & 0.092 & & \\
\hline \multicolumn{5}{|l|}{$100 \%$ Polyester $(n=5)$} \\
\hline Post-Wash & 1.326 & 0.494 & 2.702 & 0.054 \\
\hline Pre-Wash & 0.724 & 0.092 & & \\
\hline \multicolumn{5}{|l|}{ Polyester/Acrylic 50/50 (n=5) } \\
\hline Post-Wash & 20.263 & 3.404 & 11.506 & 0.001 \\
\hline
\end{tabular}




\begin{tabular}{|c|c|c|c|c|}
\hline Pre-Wash & 3.036 & 0.361 & & \\
\hline \multicolumn{5}{|c|}{ Polyester/Spandex 95/5 $(n=5)$} \\
\hline Post-Wash & 0.72 & 0.202 & 5.387 & 0.006 \\
\hline Pre-Wash & 0.132 & 0.187 & & \\
\hline \multicolumn{5}{|c|}{ Polyester/Spandex, 96/4 (n=5) } \\
\hline Post-Wash & 0.72 & 0 & 21.654 & 0.001 \\
\hline Pre-Wash & 0.026 & 0.058 & & \\
\hline \multicolumn{5}{|c|}{ Rayon/Wool/Linen 76/20/04 (n=5) } \\
\hline Post-Wash & 1.577 & 0.619 & -0.333 & 0.756 \\
\hline Pre-Wash & 1.684 & 0.363 & & \\
\hline
\end{tabular}

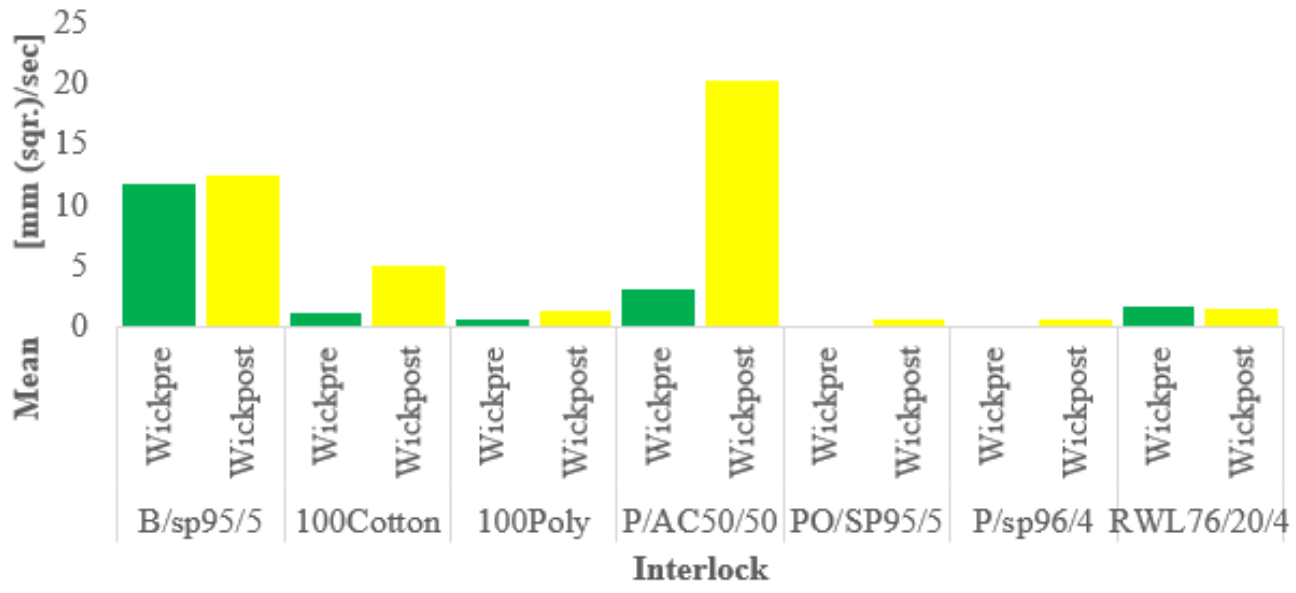

Figure 3: Pre- post horizontal wicking results for interlock knits.

Hypothesis 4: Cotton and polyester will differ for horizontal wicking of 100\% cotton (light), 100\% cotton (heavy), and 100\% polyester in pre-wash and post-wash forms for pique knit construction.

The findings revealed that differences were significant for light weight cotton $4.515 \mathrm{oz} / \mathrm{yd}^{2}$ (Table 1) and polyester (Table 5) and polyester. However, differences were not significant for the heavier cotton with weight of $6.449 \mathrm{oz} / \mathrm{yd}^{2}$ (Table 1). Hypothesis 4 was accepted. Results were consistent with one of the previous studies which reported that thickness and weight could be potentially responsible for such differences [8].

Table 5: T-tests for pre-post horizontal wicking for pique knits for different weight cottons and polyester.

\begin{tabular}{|c|c|c|c|c|}
\hline $\begin{array}{l}\text { Pique/Post/Pre/ } \\
\text { Fiber Content }\end{array}$ & $\begin{array}{l}\text { Mean } \mathrm{mm}^{2} / \\
\text { sec }\end{array}$ & $\begin{array}{l}\text { Standard } \\
\text { Deviation }\end{array}$ & t-Value & p-Value \\
\hline \multicolumn{5}{|c|}{$100 \%$ Cotton 4.515 ozs $/ \mathrm{yd}^{2}(\mathrm{n}=5)$} \\
\hline Post Wash & 14.601 & 1.583 & 17.579 & 0.001 \\
\hline Prewash & 1.381 & 0.114 & & \\
\hline \multicolumn{5}{|c|}{$100 \%$ Cotton $6.449 \mathrm{ozs} / \mathrm{yd}^{2}(\mathrm{n}=5)$} \\
\hline Post Wash & 13.583 & 1.254 & -2.296 & 0.084 \\
\hline Prewash & 15.946 & 1.696 & & \\
\hline \multicolumn{5}{|c|}{$100 \%$ Polyester $(n=5)$} \\
\hline Post Wash & 8.519 & 1.991 & 8.52 & 0.001 \\
\hline Prewash & 1.15 & 0.354 & & \\
\hline
\end{tabular}

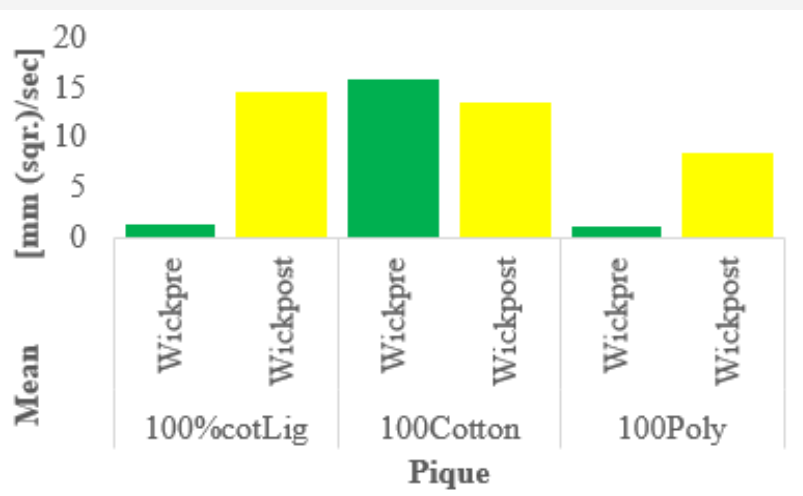

Figure 4: Pre post horizontal wicking results Pique knits.

Observing Figure 4 reflects that wicking was highest for the light-weight cotton followed by heavy weight cotton and polyester. This finding is consistent with common assumption that cotton is more absorbent than polyester and should have better wicking ability also [17]. However, prior research did not talk about the impact of fabric weight on the wicking behavior. Hussain et al. noted that irregular pique knit has superior wicking and moisture management properties [14]. Vasconcelos et al. reported that double-faced knitted construction has better moisture management than single constructions [11]. Pique knit was used as one of the examples by the scholars. Reduction in the post wash could be function of reduced stitch length and porosity that could impact 
transportation of liquid through capillary action adversely. Another publication reported that cotton is good at holding moisture. However, it may not have good wicking ability. In contrast, synthetic fibers are quick drying and can be engineered to have better wicking ability [29].

Hypothesis 5: No difference will exist between 100\% cotton in jersey, interlock and pique knit in pre and post wash for horizontal wicking.

Repeated measure analysis with one factor revealed that main effects of wash $\left(\mathrm{F}_{1,12}=420.030, \mathrm{p}<.001\right)$ and structure $(\mathrm{F} 1,12$ $=263.03, \mathrm{p}<.001$ ) were significant for $100 \%$ cotton (wash same was true for interactions between wash and structure. There was sufficient evidence to conclude that differences between pre and post horizontal wicking were dependent on structure (jersey, interlock, and pique). ( $\mathrm{F}_{1,12}=173.44, \mathrm{p}<.001$ ). Tukey's HSD comparisons revealed that Differences were also significant $(\mathrm{p}<.001)$ between interlock and pique, jersey and pique, and jersey and interlock knits. As indicated by the interaction plot (Figure 5), the differences between pre and post tests were greatest for pique followed by interlock and jersey knit. Overall, hypothesis 5 was rejected. For the reported study, wicking was highest for pique knit followed by interlock and jersey knit. These findings are somewhat consistent with one previous study which reported that pique knits have higher wicking due to its irregular surfaces [30]. Extending this work to rib and warp knits will extend this understanding even further.

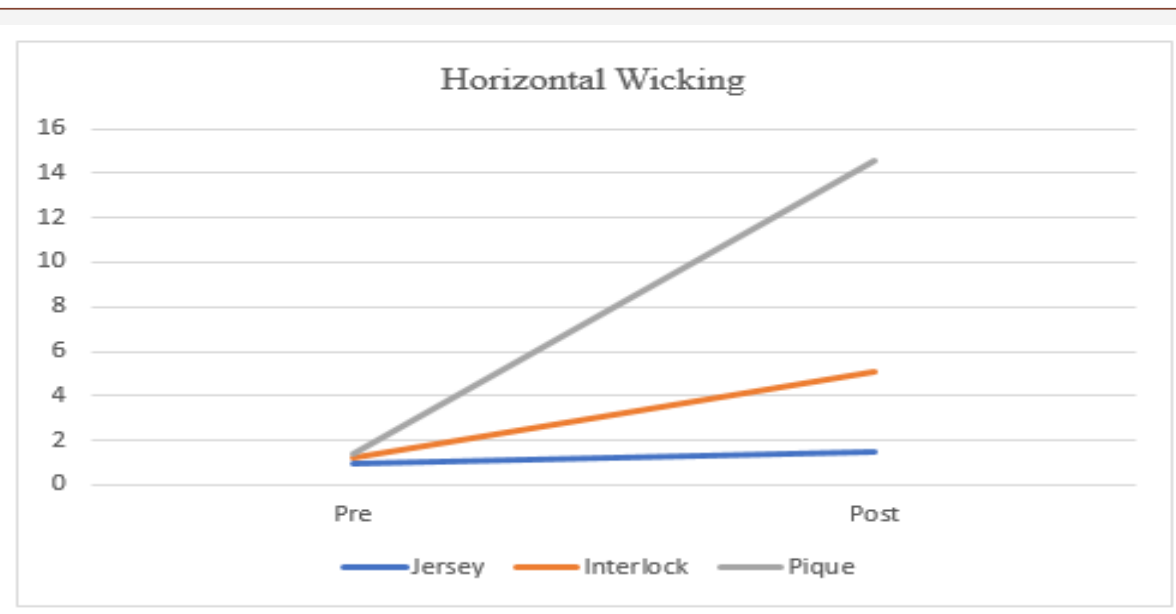

Figure 5: Interaction plot with wash and structure for horizontal wicking for $100 \%$ cotton.

Hypothesis 6: Horizontal wicking is function of fabric thickness, weight and count.

Adjusted $\mathrm{R}^{2}$ for pre-wicking were .20 for interlock knits, -.085 for jersey knits and .98 for pique knits (Table 6). For post wicking, it was .794 for interlock knits, -.067 for jersey knits, and .699 for

Table 6: Regression results for three types of knits in pre and post wash for horizontal wicking

\begin{tabular}{|c|c|c|c|c|c|c|}
\hline Type of Knit & Prewash Beta & Pre-wash $\mathrm{t}$ & Pre-wash p & Post-Wash Beta & Post-Wash t & Post-Wash p \\
\hline Interlock & & 2.21 & 0.035 & & 7.284 & $<.001$ \\
\hline Thickness & -6.336 & -2.398 & 0.023 & 0.128 & 0.052 & 0.959 \\
\hline Weight & 0.337 & 0.656 & 0.516 & -1.077 & -2.24 & 0.032 \\
\hline Count & -0.096 & -2.606 & 0.014 & -0.384 & -11.083 & $<.001$ \\
\hline Jersey & & 0.372 & 0.712 & & 0.442 & 0.662 \\
\hline Thickness & -4.333 & -0.316 & 0.754 & -4.172 & -0.225 & 0.823 \\
\hline Weight & 0.632 & 0.543 & 0.591 & 1.461 & 0.928 & 0.36 \\
\hline Count & -0.023 & -0.212 & 0.833 & -0.061 & -0.418 & 0.679 \\
\hline Pique & & -6.572 & 0.001 & & 0.95 & 0.362 \\
\hline Thickness & 34.829 & 2.792 & 0.018 & 10.555 & 0.496 & 0.629 \\
\hline Weight & 3.641 & 3.019 & 0.012 & -0.45 & -0.219 & 0.831 \\
\hline Count & 0.288 & 3.865 & 0.003 & -0.097 & 0.764 & 0.461 \\
\hline
\end{tabular}

Interpretation for the association between weight, count, and thickness, and pre and post wash for interlock and pique knit is provided below. For interlock knits, the coefficient of thickness was -6.336 . Therefore, for every unit increase in thickness 6.336

units decrease in the pre-wash, holding both weight and count to be constant. The coefficient for count was -0.96 . It suggests that for every unit increase in count, .096 units decrease will happen in prewash holding thickness and weight constant. The coefficient 
for weight was -1.077 . This indicates that for every unit increase in weight, one can expect a decrease of approximately 1.077 units in the post-wash, holding both thickness and count to be constant. Likewise, the coefficient of -.384 for count suggests that every unit increase in count will result in a decrease of approximately .384 in the post wash holding thickness and weight constant.

For pique knit, explanation is provided only for pre-wash setting because it was significant. Coefficient for thickness of 34.829 indicates that a unit increase in thickness will result in same value increase for pre-washing assuming weight and count are constant. Likewise, an increase in weight will result in the coefficient of 3.641 will result in increase in horizontal wicking in the pre-washing stage assuming count and thickness are constant. Finally, coefficient for count was .288 which indicates that one unit increase in count will result in .288 unit increase for prewashing assuming weight and thickness are constant. No association is provided for jersey knit and post wash for pique knit because they were not significant at $\mathrm{p}<.05$ level. These statistical findings allow us to determine relationship between horizontal wicking and three structural attributes in a meaningful manner despite there were differences in the three structural attributes due to differences in fiber content.

Specifically, for pre-wash stage, thickness and count contributed the wicking ability of interlock knits, and all three attributes for the pique knits. For post-wash significant contributions were made only by weight and count for interlock knits. Results could be function of more complex knit structure for interlock and pique knits that allows more area to spread water through capillaries than the jersey knit. Interlock knits provide a stable structure and look alike on both sides. These findings are consistent with Nazir e al. who reported that stretched loops of longer stitches improve air permeability by increased porosity and reduce the wicking ability [15]. These researchers reported on interlock knits only and did not examine jersey and pique knits.

\section{Conclusions}

Findings revealed that in pre-wash setting, wicking was lowest polyester and highest for $100 \%$ cotton in pique kit, lowest for poly/ spandex and highest for bamboo/spandex for interlock knit, and highest for cotton/polyester (50/50 blend) and lowest for 60/40 cotton/polyester (60/40) blend for jersey knits. In post-wash setting, it was lowest for poly/spandex in jersey and interlock construction and for $100 \%$ polyester in piques knit. The horizontal wicking was highest for light cotton in pique knit, polyester/acrylic for interlock knit and cotton/polyester for jersey knits. These findings were partially consistent with one of the previous research studies which reported that elastane had poor wicking ability [31]. Findings were inconsistent regarding best wicking ability of rayon and better performance of polyester than polypropylene. One of the recent publications found that cotton/spandex blend in jersey had significantly higher horizontal wicking than rayon/spandex and polyester/spandex blends [21]. Four of the six hypotheses were rejected. Fabric count and thickness contributed toward wicking ability of interlock knits. All three structural attributes (fabric count, fabric thickness and fabric weight) contributed toward wicking of the pique knits. They were $20 \%$ for interlock, $4.9 \%$ for jersey knit and $98 \%$ for the pique knits for pre-wash setting. However, they were 79.4\%, 9.2\% and 69.9\% for interlock, jersey, and pique knits respectively for post-washing. They improved for interlock and jersey knits and decreased for the pique knit. Increase in post washing wicking for jersey knit is consistent with previous research study which found that there was no difference between $100 \%$ cotton and 50/50 cotton/polyester blend jersey knit t-shirts in pre-wash condition [7]. However, they differed significantly for the post-wash condition. Another study of three brands of $100 \%$ cotton $t$-shirts also observed increase wicking ability after repeated washes [4]. Pre-post wicking by knit structure for $100 \%$ cotton revealed that it was highest for the pique knit pique knit followed by interlock and jersey knit for the reported study.

Even though bamboo is not classified as fabric, retailers sell products as bamboo or bamboo blends and have tested and reported them in published work. Therefore, researchers used that as a fiber content in the reported study. Retailer of fabrics sold one of the fabrics as bamboo/spandex blend. Wardingsih and Troynikov [11] used the term bamboo fabrics in their study and Basit, et al. [32] tested $100 \%$ bamboo fibers as well as $50 \% / 50 \%$ blend of bamboo/ rayon as blends of cotton, modal rayon, Tencel and viscose rayon. They examined tenacity, elongation, tear strength, air permeability and moisture management. Their findings revealed that Tencel had the highest moisture management. The bamboo-Tencel had higher values than bamboo-cotton. In this study, blends with both types of rayon yielded lower moisture management than Tencel. Kandhavadivu, Rathinamoorthy, and Surjit compared woven and knitted fabrics and found that wicking ability of three-layered (bamboo, charcoal and lyocell) weft knitted fabrics was higher than the woven materials [29]. So was true for the fabric made from bamboo/polyester/lyocell combination. None of these studies tested the Bamboo spandex blend.

The reported study has provided some understanding about the impact of fiber content and fabric construction on horizontal wicking, Future research could answer the following questions by using better control of structural attributes than was possible with purchased fabrics. This could be accomplished by going to the textile manufacturers for tight control of structural attributes. Does cotton wick better than polyester? Do knits wick better than woven fabrics? How do twists/crimps per inch impact wicking ability of different fiber contents and fabric constructions? How will rib knit with similar structural attributes perform for horizontal wicking? What is the impact of finishes on the wicking of different fiber contents? Does fabric weight influence wicking ability of other fabrics? Do vertical and horizontal wicking yield similar results?

\section{Acknowledgement}

Authors thank Islam Md Rashedul, Graduate Research Assistant for creating figures for the manuscript. 


\section{Conflict of Interest}

No conflict of interest.

\section{References}

1. Cohen AC, Johnson I (2014) Fabric Science; Fairchild: New York, NY, USA, p.133.

2. Saricam C (2015) Absorption, Wicking and Drying Characteristics of Compression Garments. Journal of Engineered Fibers and Fabrics 10(3): 146-154.

3. Uttam D, Sethi R (2016) The Effect of Repeated Washings on The Total Hand Value of Cotton Fabric (2016) International Journal of Research in Engineering and Applied Sciences 6(2): 126-135.

4. Chowdhary U (2017) Comparing Three Brands of Cotton T-Shirts. AATCC Journal of Research 4(3): 22-33.

5. Tortora PG, Merkel RS (2003) Fairchild's Dictionary of Textiles. Fairchild: New York, NY, USA, pp 629-630.

6. (2016) AATCC Technical Manual; AATCC: Research Triangle Park, NC, USA, 91: 396-398.

7. Marsha SS, Chowdhary U (2018) Comparison of Selected Structural and Performance Attributes of Cotton and Cotton/Polyester Blend T-Shirts. SSRG Journal of Polymer and Textile Engineering 5(3): 40-49.

8. Telli A, Ozdil N (2015) Effect of Recycled PET Fibers on the Performance Properties of Knitted Fabrics. Journal of Engineered Fibers and Fabrics 19(2): 47-60.

9. Chowdhary U, Adnan MM, Cheng C (2018) Bursting Strength and Extension for Jersey, Interlock and Pique Knits. Trends in Textile Engineering and Fashion Technology 1(2): 1-9.

10. Ashraf M, Siyal MI, Nazir A, Rehman A (2017) Single-Step Antimicrobial and Moisture Management Finishing of Pc Fabric Using Zno Nanoparticles. Autex Research Journal 17(3): 259-262.

11. de Vasconcelos FB, Monteiro de Barros LM, Borelli C, de Vasconcelos FG (2017) Moisture Management Evaluation in Double Face Knitted Fabrics with Different Kind of Constructions and Fibers. Journal of Fashion Technology and Textile Engineering S3: 009.

12. Messiry ME, Ouffy AE, Issa M (2015) Microcellulose particles for surface modification to enhance moisture management properties of polyester, and polyester/cotton blend fabrics Alexandria Engineering Journal 54(2): 127-140.

13. Jhanji Y, Gupta D, Kothari VK (2015) Moisture management properties of plated knit structures with varying fiber types. The Journal of Textile Institute 106(6): 663-673.

14. Hussain T, Nazir A, Masood R (2015) In Proceedings, $3^{\text {rd }}$ International Conference on Value Addition \& Innovation in Textiles (Covitex-2015) National Textile University Faisalabad Pakistan, pp 15-26.

15. Nazir A, Hussain T, Ahmad F, Faheem S (2014) Effect of Knitting Parameters on Moisture Management and Air Permeability of Interlock Fabrics. AUTEX Research Journal 14(1): 39-46.
16. Öner E, Okur A (2014) The effect of different knitted fabrics' structures on the moisture transport properties. The Journal of Textile Institute 104(11): 1164-1177.

17. Wardingsih W, Troynikov 0 (2012) Influence of cover factor on liquid moisture transport performance of bamboo knitted fabrics. The Journal of the Textile Institute 103(1): 89-98.

18. Senthikumar M, Sampath MB, Ramachandran T (2013) Moisture Management in an Active Sportswear: Techniques and Evaluation-A Review Article. Journal of The Institution of Engineers (India): Series E 93(2): 61-68.

19. Cimilli S, Nergis B, Candan C, Ozdemir M (2009) A Comparative Study of Some Comfort-related Properties of Socks of Different Fiber Types. Textile Research Journal 80(10): 948-957.

20. Morent R, Geyter ND, Leys C, Vansteenkiste E, Bock JD, et al. (2006) Measuring the wicking behavior of textiles by the combination of a horizontal wicking experiment and image processing. Review of Scientific Instruments 77, 093502.

21. Kundu SK, Chowdhary U (2018) Effect of Fiber Content on Comfort Properties of Cotton/Spandex, Rayon/Spandex, and Polyester/Spandex Single Jersey Knitted Fabrics. SSRG Journal of Polymer and Textile Engineering 5(3): 33-39.

22. (2017) ASTM 1777- 96 (reapproved 16, ASTM International, West Conshohocken, PA, USA.

23. (2017) ASTM D3776/3776M - 09a (Reapproved 2017). ASTM International, West Conshohocken, PA, USA.

24. (2009) ASTM 3887-, ASTM International, West Conshohocken, PA, USA.

25. (2017) ASTM 1776-16, ASTM International, West Conshohocken, PA, USA.

26. Merkel RS (1991) Textile product serviceability. Macmillan: New York, USA, p. 387.

27. Kasdan R, Kornblum S (1998) Synthetic Knit Fabric Having Superior Wicking and Moisture Management Properties. US Patent $6,427,493.2002$.

28. Chatterjee A, Singh P (2014) Studies on Wicking Behaviour of Polyester Fabric. Journal of Textiles Volume 2014: 1-11.

29. (2019) Cotton versus synthetic: why the natural choice may not be cotton.

30. Kasdan R, Kornblum S (1998) Synthetic Knit Fabric Having Superior Wicking and Moisture Management Properties. US Patent $6,427,493.2002$.

31. Fangueiro R, Filgueiras A, Soutinho F, Meidi X (2010) Wicking Behavior and Drying Capability of Functional Knitted Fabrics. Textile Research Journal 80(15): 1522-1530.

32. Basit A, Latif W, Baig SA, Afzal A (2018) The Mechanical and Comfort Properties of Sustainable Blended Fabrics of Bamboo with Cotton and Regenerated Fibers. Clothing and Textiles Research Journal 36(4): 267280. 